\title{
AUTUN, Chartes de l'abbaye Saint-Martin
}

J.-Gabriel Bulliot, Essai historique sur l'abbaye de St.-Martin d'Autun.

Chartes et pièces justificatives, Autun, 1849.

Karl Heidecker

\section{(2) OpenEdition}

Journals

Édition électronique

URL : https://journals.openedition.org/cem/2562

DOI : $10.4000 /$ cem. 2562

ISSN : 1954-3093

Éditeur

Centre d'études médiévales Saint-Germain d'Auxerre

Référence électronique

Karl Heidecker, «AUTUN, Chartes de l'abbaye Saint-Martin », Bulletin du centre d'études médiévales d'Auxerre / BUCEMA [En ligne], Collection CBMA, mis en ligne le 02 octobre 2007, consulté le 24 septembre 2022. URL : http://journals.openedition.org/cem/2562 ; DOI : https://doi.org/10.4000/cem. 2562

Ce document a été généré automatiquement le 24 septembre 2022.

\section{(1) $(\mathcal{Q} \odot$}

Creative Commons - Attribution - Pas d'Utilisation Commerciale - Partage dans les Mêmes Conditions 4.0 International - CC BY-NC-SA 4.0

https://creativecommons.org/licenses/by-nc-sa/4.0/ 


\section{AUTUN, Chartes de l'abbaye Saint- Martin}

J.-Gabriel Bulliot, Essai historique sur l'abbaye de St.-Martin d'Autun. Chartes et pièces justificatives, Autun, 1849.

\section{Karl Heidecker}

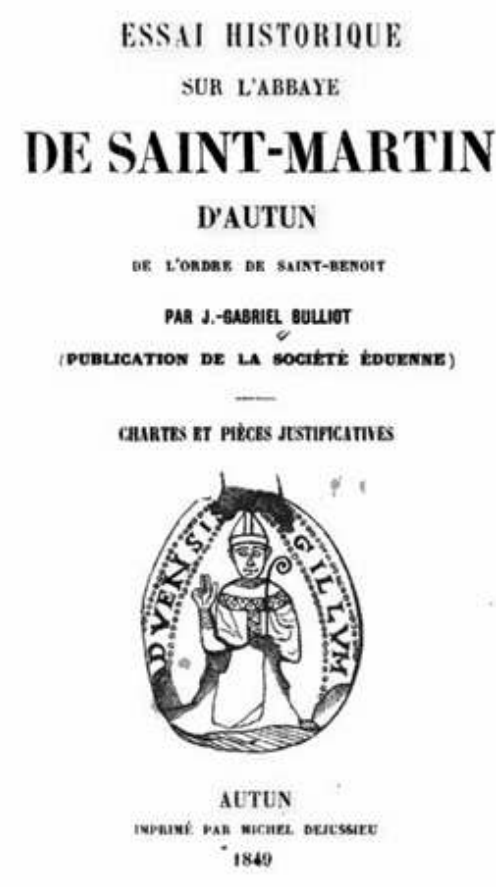

1 L'édition est faite d'après des originaux et de « vieilles copies ». L'éditeur a utilisé aussi un cartulaire du XV siècle, composé sur l'ordre de Jean Rolin (Paris, BnF, ms. lat. 05422 ; IRHT 38886 ;Stein 0275) qui contient des actes datés à partir de l'année 1170. Parmi les actes antérieurs à 1300, un seul acte est retenu, l'éditeur jugeant les autres 
sans interêt. On peut supposer que l'éditeur a écarté des actes relatifs aux domaines économiques et sociaux.

2 L'éditeur dit d'avoir transcrit les actes sans corriger l'orthographe, même si elle était contradictoire: "Nous nous sommes efforcé de les reproduire avec la plus grande exactitude, sans changer les différentes orthographes souvent contradictoires dans la même pièce." L'édition contient 165 actes au total, concernant les années 856-1677. 99 actes sont antérieurs à 1300 , ils sont classés chronologiquement. Un supplément de 18 actes complète l'ensemble pour les années 1286-1824. Très souvent l'editeur ne mentionne pas d'après quelle source il a travaillé, et la qualité de ses transcriptions est inégale.

3 Les 13 premiers actes, c'est à dire les actes antérieurs à 1161, ont été édités de façon plus satisfaisante par d'autres éditeurs. Les actes $\mathrm{n}^{\mathrm{os}} 2,3,6,7,8,10,11$ et 13 sont à consulter dans les éditions des Chartes et diplômes des rois de France et l'acte $\mathrm{n}^{\circ} 18$ dans Papsturkunden in Frankreich II, éd. W. Wiederhold. L'acte $\mathrm{n}^{\circ} 5$ figure dans la base de l'ARTEM sous le $\mathrm{n}^{\circ} 4766$, et a été édité par Charmasse dans le volume 1 du Cartulaire de l'église d'Autun (2e partie, $\mathrm{n}^{\circ} 1, \mathrm{p} .85-86$ ). L'acte $\mathrm{n}^{\circ} 1$ est un texte narratif transcrit par dom Mabillon. L'acte $n^{\circ} 9$ n'est pas un acte diplomatique non plus, mais le texte d'une association de prières pris dans un manuscrit $\mathrm{du}_{\mathrm{XV}} \mathrm{X}^{\mathrm{e}}$ siècle. Enfin l'acte $\mathrm{n}^{\circ} 12$ n'est pas un acte du XIe siècle, mais il est postérieur au XI ${ }^{\mathrm{e}}$ siècle.

Le texte de ce cartulaire est mis à disposition sur le site web d'ARTeHIS. 